\title{
Interleukin-11 Receptor Is a Candidate Target for Ligand-Directed Therapy in Lung Cancer
}

\section{Analysis of Clinical Samples and BMTP-11 Preclinical Activity}

\author{
Marina Cardó-Vila, ${ }^{* \dagger \ddagger}$ Serena Marchiò, ${ }^{* \dagger \ddagger \S \rrbracket ~ M a s a n o r i ~ S a t o, ~ F e r n a n d a ~ I . ~ S t a q u i c i n i, ~}{ }^{* \dagger \ddagger}$ Tracey L. Smith, ${ }^{* \dagger \dagger}$ Julianna K. Bronk, ${ }^{* *}$ \\ Guosheng Yin ${ }^{\dagger \dagger}$ Amado J. Zurita, ${ }^{* *}$ Menghong Sun, ${ }^{\ddagger}$ Carmen Behrens, ${ }^{\S \S}$ Richard L. Sidman, ${ }^{\natural \top}$ J. Jack Lee, ${ }^{\dagger \dagger}$ Waun K. Hong, \\ Ignacio I. Wistuba, ${ }^{* * *}$ Wadih Arap, ${ }^{* \dagger \dagger \dagger}$ and Renata Pasqualini ${ }^{* \dagger \ddagger}$
}

From the University of New Mexico Comprehensive Cancer Center* and the Divisions of Molecular Medicine ${ }^{\dagger}$ and Hematology/Oncology, ${ }^{\dagger \dagger}$ Department of Internal
Medicine, ${ }^{\ddagger}$ University of New Mexico School of Medicine, Albuquerque, New Mexico; the Department of Oncology, ${ }^{\S}$ University of Turin, Turin, Italy; the Candiolo
Cancer Institute-IRCCS, ${ }^{\Phi}$ Candiolo, Italy; the First Surgery Department, ${ }^{\|}$Hamamatsu University School of Medicine, Hamamatsu, Japan; the Division of Cancer
Medicine, ${ }^{\|\| \|}$Departments of Genitourinary Medical Oncology, ${ }^{* *}$ Biostatistics, ${ }^{\dagger \dagger}$ Thoracic/Head and Neck Medical Oncology, ${ }^{\S \S}$ and Translational Molecular
Pathology, ${ }^{* * *}$ The University of Texas M.D. Anderson Cancer Center, Houston, Texas; the Tissue Bank and Department of Pathology, ${ }^{\ddagger \ddagger}$ Fudan University Shanghai
Cancer Center, Shanghai, China; and the Department of Neurology, ${ }^{\uparrow \uparrow}$ Harvard Medical School and Beth Israel Deaconess Medical Center, Boston, Massachusetts

Accepted for publication

April 8, 2016.

Address correspondence to Renata Pasqualini, Ph.D., or Wadih Arap, M.D., Ph.D., MSC07-4025, 1 University of New Mexico, 1201 Camino de Salud NE, Albuquerque,

NM 87131. E-mail: rpasqual@ salud.unm.edu or warap@salud. unm.edu.

\begin{abstract}
We previously isolated an IL-11-mimic motif (CGRRAGGSC) that binds to IL-11 receptor (IL-11R) in vitro and accumulates in IL-11R-expressing tumors in vivo. This synthetic peptide ligand was used as a tumortargeting moiety in the rational design of BMTP-11, which is a drug candidate in clinical trials. Here, we investigated the specificity and accessibility of IL-11R as a target and the efficacy of BMTP-11 as a ligandtargeted drug in lung cancer. We observed high IL-11R expression levels in a large cohort of patients $(n=368)$. In matching surgical specimens (i.e., paired tumors and nonmalignant tissues), the cytoplasmic levels of IL-11R in tumor areas were significantly higher than in nonmalignant tissues $(n=36$; $P=0.003$ ). Notably, marked overexpression of IL-11R was observed in both tumor epithelial and vascular endothelial cell membranes $(n=301 ; P<0.0001)$. BMTP-11 induced in vitro cell death in a representative panel of human lung cancer cell lines. BMTP-11 treatment attenuated the growth of subcutaneous xenografts and reduced the number of pulmonary tumors after tail vein injection of human lung cancer cells in mice. Our findings validate BMTP-11 as a pharmacologic candidate drug in preclinical models of lung cancer and patient-derived tumors. Moreover, the high expression level in patients with non-small cell lung cancer is a promising feature for potential translational applications. (Am J Pathol 2016, 186: 2162-2170; http://dx.doi.org/10.1016/j.ajpath.2016.04.013)
\end{abstract}

Lung cancer is the most common malignant tumor worldwide and the leading cause of death for both men and women. $^{1-4}$ Non-small cell lung cancer (NSCLC), the most diffuse type of lung carcinoma, is only modestly responsive to chemotherapy and is therefore generally treated by surgical resection, if possible, at least for early clinical stages.

\footnotetext{
Supported by the Department of Defense grant W81XWH-05-2-0027 (W.K.H., I.I.W., W.A., and R.P.); the Gillson-Longenbaugh Foundation and the Marcus Foundation (W.A. and R.P.); The University of Texas Lung Specialized Programs of Research Excellence grant P50CA70907 (I.I.W.); and MD Anderson's Institutional Tissue Bank Award 2P30CA016672 (I.I.W.) from the National Cancer Institute.

M.C.-V., S.M., and M. Sa. contributed equally to this work.

Disclosures: At the time of the study, R.P., W.A., and The University of Texas MD Anderson Cancer Center owned equity stock in
}

Alvos Therapeutics (Arrowhead Research Corporation, Pasadena, CA). Arrowhead Research Corporation has licensed rights to patents and technologies described in this article. W.A. and R.P. report research sponsorship, including grants, and other support from Arrowhead Research Corporation and were shareholders in the company at the time of the study. The University manages and monitors the terms of these arrangements in accordance with its conflict of interest policies. 
Although cytotoxic combination chemotherapy is still used in advanced and metastatic stage and as neo-adjuvant or adjuvant treatment of earlier stages, target therapies have been increasingly used in NSCLC toward personalized treatments. ${ }^{5}$ Large randomized clinical trials demonstrated a benefit from the introduction of the antiangiogenic drug bevacizumab in combination therapy, ${ }^{6}$ as well as cetuximab in patients with epidermal growth factor receptor-expressing tumors. ${ }^{7,8}$ Furthermore, small-molecule inhibitors, such as gefitinib ${ }^{9}$ or crizotinib, ${ }^{10}$ are options for NSCLC patients with epidermal growth factor receptor mutations or echinoderm microtubule-associated protein-like 4-anaplastic lymphoma kinase translocations, respectively. However, despite improvements in therapeutic approaches, the survival expectation for patients with advanced NSCLC remains only 16 to 24 months. ${ }^{1}$ Thus, given the high incidence and rate of mortality associated with this tumor, new molecular targets are an unmet need.

Through the selection of circulating combinatorial phage display libraries in a terminal wean patient with cancer, we have uncovered new tumor- and vascular-specific molecular targets. ${ }^{11-13}$ Among these, the cyclic peptide motif CGRRAGGSC (single letter code) was validated as a mimic of IL-11, mapping to a previously unrecognized binding site that interacts with IL-11 receptor (IL-11R) with consequent STAT-3 phosphorylation and cell proliferation. ${ }^{14,15}$ In addition to our previous work demonstrating elevated levels of IL-11R in prostate cancer, ${ }^{11}$ similar data have been reported in carcinomas of the breast, colon, and stomach; bone sarcomas; and leukemia/lymphomas. ${ }^{16-20}$ In preclinical models, the CGRRAGGSC peptide conjugated to a proapoptotic moiety (CGRRAGGSC-GG-D $\left[\mathrm{KLAKLAK}_{2}\right.$ ) selectively targeted prostate cancer osteoblastic metastasis, as well as osteosarcoma metastasis in the lung, while having no toxic effect on normal surrounding tissues. ${ }^{16,21}$ This formulation, termed BMTP-11, underwent evaluation in a first-in-man phase zero clinical trial, aimed at defining drug specificity, maximum tolerated dose, and limiting toxicities with promising pilot results. ${ }^{22}$

Here, we evaluate IL-11R as a molecular target in human lung cancer and propose a therapeutic approach based on the selective targeting of IL-11R. In human samples, we found increased expression of IL-11R in tumors compared with adjacent nonmalignant tissues. Overexpressed IL-11R was exposed on the tumor cell membrane and was present also in tumor vascular endothelial cells, supporting the liganddirected accessibility of this receptor from the circulation. We demonstrated that in vitro BMTP-11 efficiently targets and kills a panel of lung cancer cell lines derived from adenocarcinoma (ADC), squamous cell carcinoma (SCC), or large cell lung carcinoma. When BMTP-11 was systemically administered in vivo, we observed a significant delay in the growth of subcutaneous tumor xenografts plus a reduction in the establishment of pulmonary tumors after tail vein injection of human lung cancer cells. Taken together, these results suggest that BMTP-11 could potentially serve as an active targeted drug candidate to be evaluated in patients with lung cancer.

\section{Materials and Methods}

\section{Cell Culture}

The human lung cancer cell lines A549, H226, H460, and H522 were from the ATCC (Manassas, VA); HOP62 and HOP92 were from the National Cancer Institute, Center for Cancer Research cell repository (Bethesda, MD). Cells were cultured at $37^{\circ} \mathrm{C}$ in $5 \% \mathrm{CO}_{2}$ and maintained in RPMI 1640 supplemented with 5\% fetal bovine serum (ThermoFisher Scientific, Waltham, MA), $5 \mathrm{mmol} / \mathrm{L}$ L-glutamine, and antibiotics $(100 \mathrm{U} / \mathrm{mL}$ penicillin $\mathrm{G}$ and $100 \mathrm{mg} / \mathrm{mL}$ streptomycin; ThermoFisher Scientific).

\section{Flow Cytometry}

Exponentially growing cells were harvested, washed with phosphate-buffered saline (PBS), and resuspended in ice-cold PBS that contained $1 \%$ bovine serum albumin. Human Fc Receptor Blocking Reagent (Miltenyi Biotec, San Diego, CA) was added to each cell suspension $\left(20 \mu \mathrm{L}\right.$ per $1 \times 10^{7}$ cells $)$ and incubated for 10 minutes on ice. Next, $20 \mu \mathrm{L}$ of either anti-human IL-11R $\alpha$-phycoerythrin-labeled antibody (Clone N-20; Santa Cruz Biotechnology, Dallas, TX) or phycoerythrinconjugated rabbit IgG isotype control (GeneTex, Irvine, CA) was added per $1 \times 10^{6}$ cells in $100 \mu \mathrm{L}$ of PBS that contained $1 \%$ bovine serum albumin and incubated at $4{ }^{\circ} \mathrm{C}$ for 1 hour. Subsequently, cells were washed with PBS that contained $1 \%$ bovine serum albumin and analyzed with a BDFACSCanto flow cytometer (BD Biosciences, Franklin Lakes, NJ).

\section{Cell Viability and Apoptosis Assays}

Cells were grown to 95\% confluence in 96-well plates (Fisher Scientific, Pittsburgh, PA). Serial molar concentrations of either BMTP-11 or nontargeted ${ }_{\mathrm{D}}[\mathrm{KLAKLAK}]_{2}$ control were added to each well to a final molar concentration of 1 to 1000 $\mu \mathrm{mol} / \mathrm{L}$. After incubation at $37^{\circ} \mathrm{C}$ for 18 hours, cell viability was assessed with the WST-1 assay (Roche Life Sciences, Indianapolis, IN). Values obtained in test conditions were normalized to negative controls and were expressed as percentage values. Apoptotic cell death was evaluated with the Annexin V/PI kit (BD Biosciences, San Jose, CA) according to the manufacturer's instructions. In essence, 15,000 cells were seeded into 96-well plates, treated with serial molar concentrations of either peptide ( 1 to $1000 \mu \mathrm{mol} / \mathrm{L}$ ) for 6 hours, followed by the addition of $4 \mu \mathrm{L} /$ well of the Annexin $\mathrm{V}$ antibody. Fluorescence was quantified in a ClarioStar plate reader (BMG Labtech, Ortenberg, Germany). For both assays, reverse sigmoidal dose-response curves with variable slopes were fitted, and concentration that inhibits 50\% $\left(\mathrm{IC}_{50}\right)$ values were calculated with the Prism software version 5.0 (GraphPad Software, Inc., La Jolla, CA). 


\section{Lung Cancer Mouse Models}

Female nude BALB/c mice were from Harlan Laboratories (Indianapolis, IN). The H460 human lung cancer cell line is a well-established model, known to produce consistent subcutaneous tumors and lung tumors after intravenous administration. A subcutaneous model was obtained by implantation of $10^{6} \mathrm{H} 460$ cells into the flank; expression of IL-11R in these tumors was confirmed by immunohistochemistry (IHC). Treatment consisted of injections of 10 $\mathrm{mg} / \mathrm{kg}$ of either BMTP-11 or nontargeted ${ }_{\mathrm{D}}[\text { KLAKLAK }]_{2}$ peptide ( $n=10$ per group) at days 3 and 10 after tumor implantation. Tumor sizes were serially measured with a digital caliper, and tumor volumes were calculated. ${ }^{23,24} \mathrm{~A}$ lung colonization model was established by tail vein injection of $10^{6} \mathrm{H} 460$ cells. $^{25-27}$ Again, expression of IL-11R was confirmed in lung tumors by IHC staining with an anti-IL-11R antibody. Mice were treated with BMTP-11 $(n=10)$ or nontargeted ${ }_{\mathrm{D}}\left[\mathrm{KLAKLAK}_{2}\right.$ peptide $(n=9)$ as described above in this section and sacrificed 15 days after tumor cell injection. Lungs were recovered, weighed on a digital scale, formalin-fixed, and paraffin-embedded. Ten sections corresponding to different levels of the lungs were obtained, which were stained with hematoxylin and eosin. The number of tumors in each slide was determined by a pathologist. All animal protocols were approved by the Institutional Animal Care and Use Committee at The University of Texas MD Anderson Cancer Center, and all experiments were completed in accordance with institutional guidelines.

\section{Patient-Derived Samples}

The retrospective study was approved by the Institutional Review Board at The University of Texas MD Anderson Cancer Center. Surgical lung cancer specimens were obtained from the Lung Cancer Specialized Program of Research Excellence Tissue Bank. A panel of patientderived samples $(n=368)$ was collected from 1997 to 2001. A tissue microarray was constructed from triplicate 1-mm-diameter cores, punctured from central, intermediate, and peripheral regions of primary lung cancers $(n=327)$, as described. ${ }^{28,29}$

\section{IHC Staining}

IHC was performed on $4-\mu \mathrm{m}$ formalin-fixed paraffinembedded tissue sections. Antigen retrieval was achieved by heating in $1 \mathrm{mmol} / \mathrm{L}$ EDTA $\mathrm{pH} 8.0$ (ThermoFisher Scientific), followed by blocking in $3 \% \mathrm{H}_{2} \mathrm{O}_{2}$ for 15 minutes and Protein Block Solution (Dako Corp., Carpinteria, CA; Code X0909) for 30 minutes. The primary goat anti-human (clone K20; Santa Cruz Biotechnology; used for human tissues) or rabbit (clone C20; Santa Cruz Biotechnology; used for mouse tissues) anti-IL-11R $\alpha$ antibody was incubated for 2 hours. Staining was revealed with a secondary antibody and Envision Plus Dual Linklabeled polymer (Dako Corp.) for 30 minutes, after which time diaminobenzidine was applied for 5 minutes. Slides were counterstained with hematoxylin. IL-11R expression was evaluated by two independent expert pathologists as described. ${ }^{21,30}$ Cytoplasmic scores were obtained by multiplying a 4 -value intensity score $(0$, none; $1^{+}$, weak; $2^{+}$, moderate; $3^{+}$, strong) by the percentage of positive area. The membrane expression of IL-11R was quantified as percentage of membrane-positive cells over a total of at least 200 cells evaluated (Supplemental Table S1).
A

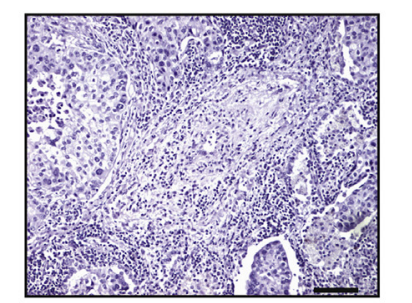

C

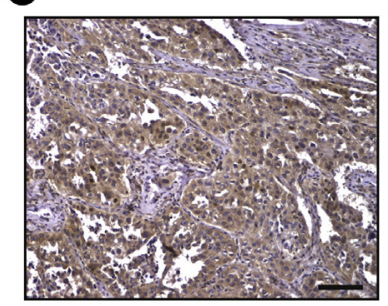

E

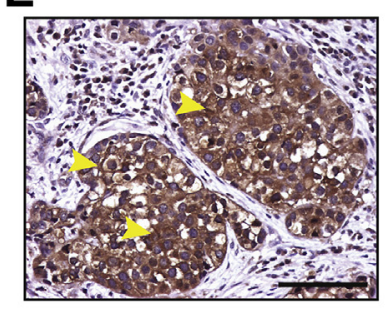

G

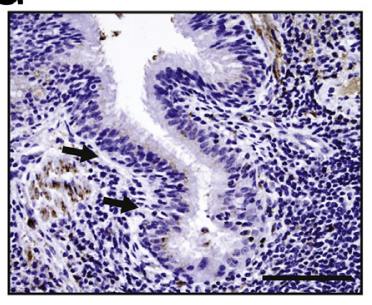

B

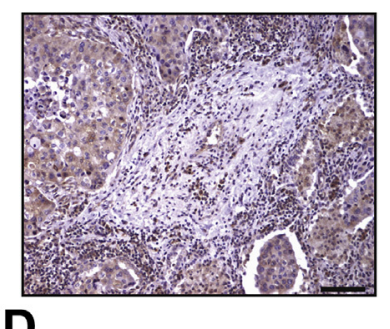

D

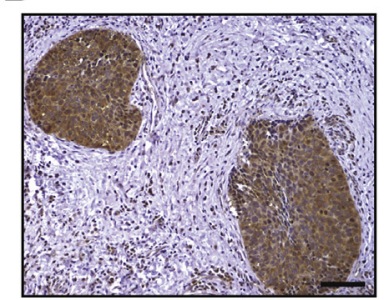

$F$

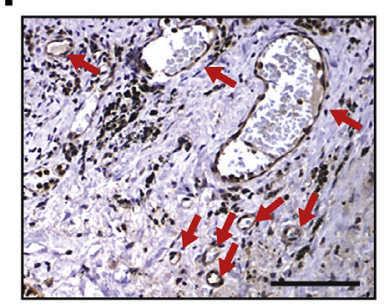

$\mathrm{H}$

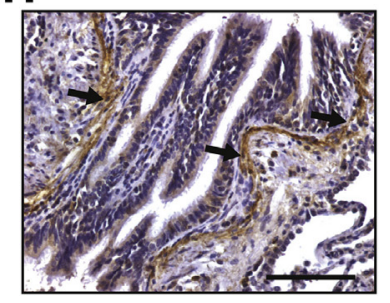

Figure 1 Immunohistochemical validation of IL-11R in human lung cancer. A-D: Negative control (secondary antibody) (A), grade $2^{+}$(B), and grade $3^{+}$(C) cytoplasmic IL-11R staining in an exemplary SCC sample; grade $3^{+}$cytoplasmic IL-11R staining in an exemplary adenocarcinoma (ADC) sample (D). E and F: Membrane positivity (arrowheads) and stromal blood vessel staining $(\mathbf{F})$ in a representative $A D C$ sample (arrows). G and H: Normal lung from a healthy donor (G) and a lung cancer patient (nonmalignant tissue adjacent to the tumor; $\mathbf{H}$ ), arrows indicate the bronchiolar wall below the basement membrane. Scale bar $=$ $100 \mu \mathrm{m}$. 


\section{Statistical Analysis}

To analyze IHC data, Wilcoxon signed rank tests were conducted to compare expressions of IL-11R in tumor specimens with nonmalignant bronchial epithelium. Linear regression models for continuous variables assuming a normal distribution and logistic regression models for binary variables were used to study the association of IL-11R expression with histology for all of the cohort patients. For patients with NSCLC $(n=301)$, either linear regression models or logistic regression models were built to characterize the association between IL-11R expression and clinical factors, including tumor pathology and smoking history. Regression analyses of survival data based on the Cox proportional hazards model were conducted on overall survival, defined as time from surgery to death or to the end of the study. The Student's $t$-test was applied to analyze all of the other data. All of the statistical tests were two-sided. $P$ values $<0.05$ were considered statistically significant. Statistical analyses were performed with the Prism software version 5.0 (GraphPad Software, Inc.).

\section{Results}

\section{IL-11R Is a Molecular Target in Human NSCLC}

To begin to define the feasibility of a BMTP-11-based therapy in human lung cancer, we first examined the expression of IL-11R in a panel $(n=41)$ of primary formalin-fixed paraffin-embedded tumors by IHC with a specific anti-IL-11R $\alpha$ antibody. This analysis revealed high cytoplasmic positivity in both SCC (Figure 1, A-C) and ADC (Figure 1D). In samples with grade $3^{+}$cytoplasmic positivity, we also observed membrane IL-11R staining and grade $3^{+}$positivity in blood vessels into the tumor stroma (Figure 1, E and F). For a subset of patient-derived samples $(n=18)$, matching nonmalignant lung tissues were also

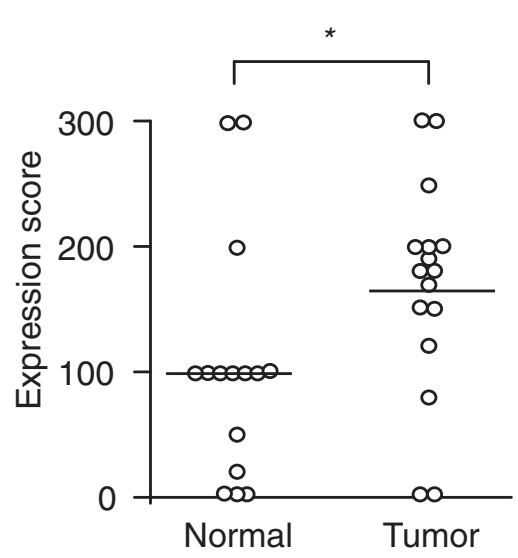

Figure 2 IL-11R expression scores in tumor and adjacent nonmalignant tissue. Comparison of the cytoplasm expression scores between lung cancer and matched adjacent nonmalignant bronchial epithelium. $n=18$ lung cancer samples; $n=18$ nonmalignant bronchial epithelium samples. ${ }^{*} P<0.01$.
Table 1 Multivariate Analysis for Patients Included in the TMA

\begin{tabular}{|c|c|c|}
\hline Characteristic & Frequency count & Total frequency, $\%$ \\
\hline \multicolumn{3}{|l|}{ Histology } \\
\hline $\mathrm{ADC}$ & 192 & 58.72 \\
\hline SCLC & 26 & 7.95 \\
\hline $\mathrm{SCC}$ & 109 & 33.33 \\
\hline \multicolumn{3}{|l|}{ Sex } \\
\hline NA & 26 & 7.95 \\
\hline Female & 162 & 49.54 \\
\hline Male & 139 & 42.51 \\
\hline \multicolumn{3}{|l|}{ Race } \\
\hline NA & 26 & 7.95 \\
\hline Caucasian & 265 & 81.04 \\
\hline Other & 36 & 11.01 \\
\hline \multicolumn{3}{|l|}{ Type of smoker } \\
\hline NA & 26 & 7.95 \\
\hline Current & 82 & 25.08 \\
\hline Former & 120 & 36.70 \\
\hline Never & 97 & 29.66 \\
\hline Unknown & 2 & 0.61 \\
\hline \multicolumn{3}{|l|}{ Pathologic M } \\
\hline NA & 26 & 7.95 \\
\hline MO & 295 & 90.21 \\
\hline M1 & 6 & 1.83 \\
\hline \multicolumn{3}{|l|}{ Pathologic N } \\
\hline NA & 26 & 7.95 \\
\hline NO & 212 & 64.83 \\
\hline N1 & 55 & 16.82 \\
\hline $\mathrm{N} 2$ & 34 & 10.40 \\
\hline \multicolumn{3}{|l|}{ Pathologic T } \\
\hline NA & 26 & 7.95 \\
\hline T1 & 114 & 34.86 \\
\hline $\mathrm{T} 2$ & 160 & 48.93 \\
\hline T3 & 16 & 4.89 \\
\hline $\mathrm{T} 4$ & 11 & 3.36 \\
\hline
\end{tabular}

$A D C$, adenocarcinoma; NA, not analyzed (low target expression); SCC, squamous cell carcinoma; SCLC, small cell lung cancer; TMA, tissue microarray.

available; the expression of IL-11R in these tumor-adjacent lung tissues was comparable with that in lung tissue from a healthy donor (Figure 1G), except for a specific region corresponding to the bronchiolar wall below the basement membrane (Figure 1H). Cytoplasmic IL-11R levels were quantified and compared between tumor and nonmalignant tissues (Figure 2), confirming the observed higher expression in tumor cells $(P=0.003)$.

These promising results prompted us to extend the analysis to a larger panel of lung cancer tissue microarray specimens (pilot, $n=327$ ) (Table 1, Supplemental Table S1). In this cohort of patients, the cytoplasmic levels of IL-11R were significantly higher in NSCLC than in SCLC (ADC or SCC versus SCLC, $P<0.0001$ ) (Table 2 ). The successive analyses were therefore focused exclusively on NSCLC samples $(n=301)$. The presence of IL-11R on the cell membrane was evaluated in 200 cells/tissue sections, revealing welldetectable positivity in approximately $25 \%$ of the cases. These same samples also exhibited higher cytoplasmic levels 
Table 2 Correlation of IL-11R Cytoplasmic Expression with Tumor Histology

\begin{tabular}{llllrrrr}
\hline & & & & \multicolumn{2}{c}{ Wald 95\% confidence limits } & \\
\cline { 5 - 6 } Variable & DF & Estimate & SEM & Lower & Upper & $\chi^{2}$ & \\
\hline Intercept & 1 & 109.7222 & 13.6401 & 82.9880 & 136.4564 & 64.71 \\
Histology & & & & & & \\
ADC & 1 & 24.0349 & 14.3245 & -4.0405 & 52.1104 & 2.82 & 0.0934 \\
SCC & 1 & 6.6667 & 14.7330 & -22.2096 & 35.5429 & 0.20 \\
SCLC & 0 & 0.0000 & 0.0000 & 0.0000 & 0.0000 & 0.6509 \\
Scale & 1 & 57.8702 & 2.3586 & 53.4273 & 62.6827 & \\
\hline
\end{tabular}

$A D C$, adenocarcinoma; DF, degrees of freedom; SCC, squamous cell carcinoma; SCLC, small cell lung cancer.

of IL-11R $(P<0.0001)$ (Table 3), suggesting that increased overall expression of IL-11R favors its allocation to the plasma membrane, where it can be targeted by liganddirected therapeutic agents (such as BMTP-11). Then, to determine whether a subset of patients would specifically benefit from BMTP-11 therapy, we first assessed IL-11R expression in association to specific clinicopathologic features. This analysis revealed that patients with ADC had higher cytoplasmic levels of IL-11R than patients with SCC $(P<0.0001)$, and patients who had ever smoked (either former or current) had higher cytoplasmic levels of IL-11R than patients who never smoked $(P=0.005)$ (Table 3$)$. These findings encourage the use of increased expression of IL-11R as a biomarker to identify patients who might benefit from IL-11R-targeted therapy.

\section{BMTP-11 Is Pharmacologically Active against Human Lung Cancer Cells in Vitro}

Having determined the pathologic presence of IL-11R as a molecular target in lung cancer, we next evaluated the activity of BMTP-11 as a ligand-directed therapy in tissue culture and preclinical mouse models. We used the human lung cancer-derived cell lines A549, H226, H460, HOP62, and HOP92. All these NSCLC lines express IL-11R on their cell surface membranes as evaluated by flow cytometry (Table 4). H522 cells were used as a negative control, showing undetectable surface expression of IL-11R. Cultured cells were treated with serial concentrations of BMTP-11 or untargeted ${ }_{\mathrm{D}}[\mathrm{KLAKLAK}]_{2}$ (control), followed by evaluation of both viability (by WST-1 assay at 18 hours after treatment) and apoptosis (by Annexin V/PI assay at 6 hours after treatment). Plots were fitted to reverse sigmoidal dose-response curves, showing that BMTP-11 reduced cell viability by inducing apoptosis in all tumor cell lines

Table 3 Associations between IL-11R Expression and Tumor Clinicopathologic Features

\begin{tabular}{lllc}
\hline Source & DF & $\chi^{2}$ & $P>\chi^{2}$ \\
\hline IL-11R localization & 1 & 23.56 & $<0.001$ \\
Histology & 1 & 15.62 & $<0.001$ \\
Type of smoker & 2 & 10.49 & 0.0053 \\
\hline
\end{tabular}

DF, degrees of freedom. examined (Figure 3, A-E). H460 (Figure 3A), HOP62 (Figure 3B), and HOP92 (Figure 3C) cells exhibited almost no residual viability when treated with $100 \mu \mathrm{mol} / \mathrm{L}$ BMTP11 , while retaining approximately $100 \%$ viability in the presence of equimolar amounts of the control peptide $\left(P<10^{-8}\right)$. Similar results were obtained with $\mathrm{H} 226$ (Figure 3D) and A549 (Figure 3E) cells at higher BMTP-11 concentrations (100 to $300 \mu \mathrm{mol} / \mathrm{L}$ ). No effect was observed in the IL-11 ${ }^{-}$cell line H522 (Figure 3F). In all other tumor cell lines examined, the $\mathrm{IC}_{50}$ for BMTP-11 was 6.3- to 11.5-fold lower than the control (Table 5). These results show that BMTP-11 is active against IL-11R-expressing human lung cancer cells in vitro, with the advantage of suitable dose range, wide therapeutic window, and broad applicability in cells derived from different lung cancer types.

\section{BMTP-11 Inhibits Tumor Growth in Vivo}

To evaluate whether BMTP-11 can target tumors and exert antitumor activity in vivo, we set up two preclinical models, obtained by injection of $\mathrm{H} 460$ cells into the flank (subcutaneous xenograft) or through the tail vein (lung colonization model) of immunodeficient mice. The expression of IL-11R was assessed by IHC, confirming, in both models, the high levels observed in clinical samples (Figure 4, A and B) and the presence on the cell surface (Figure 4B). We administered systemic BMTP-11 treatment to subcutaneous tumor xenograft-bearing mice, followed by evaluation of tumor volumes. The therapeutic effect of BMTP-11 was tested on two cohorts of mice randomized in the following

Table 4 Membrane Expression of IL-11R in Human Lung Cancer Cell Lines

\begin{tabular}{lll}
\hline & \multicolumn{2}{l}{${\mathrm{IL}-11 \mathrm{R}^{+} \text {cells, } \%}$} \\
\cline { 2 - 3 } Cell lines & Anti-human IL-11R & Control Ab \\
\hline H460 & 10.3 & 0.3 \\
H0P62 & 2.2 & 0.3 \\
H0P92 & 3.4 & 0.3 \\
H226 & 20.6 & 0.4 \\
A549 & 12.2 & 0.3 \\
H522 & 0.0 & 0.3 \\
\hline
\end{tabular}

Ab, antibody. 

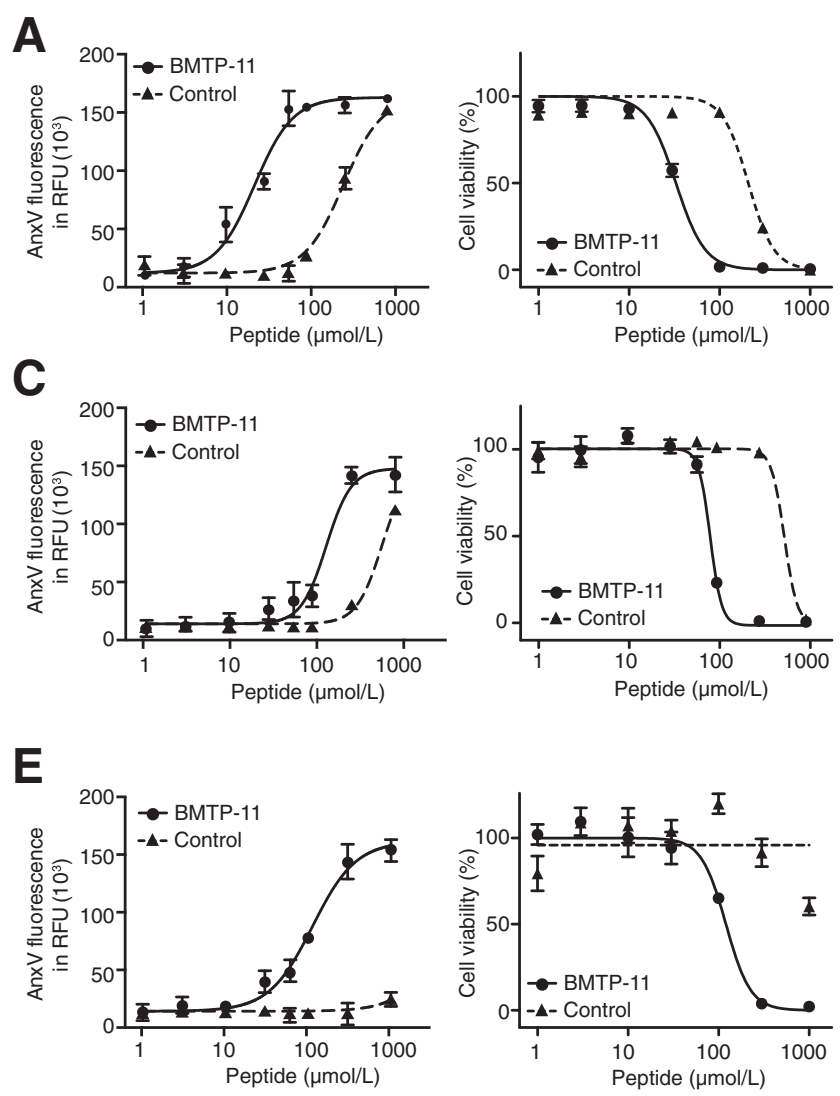
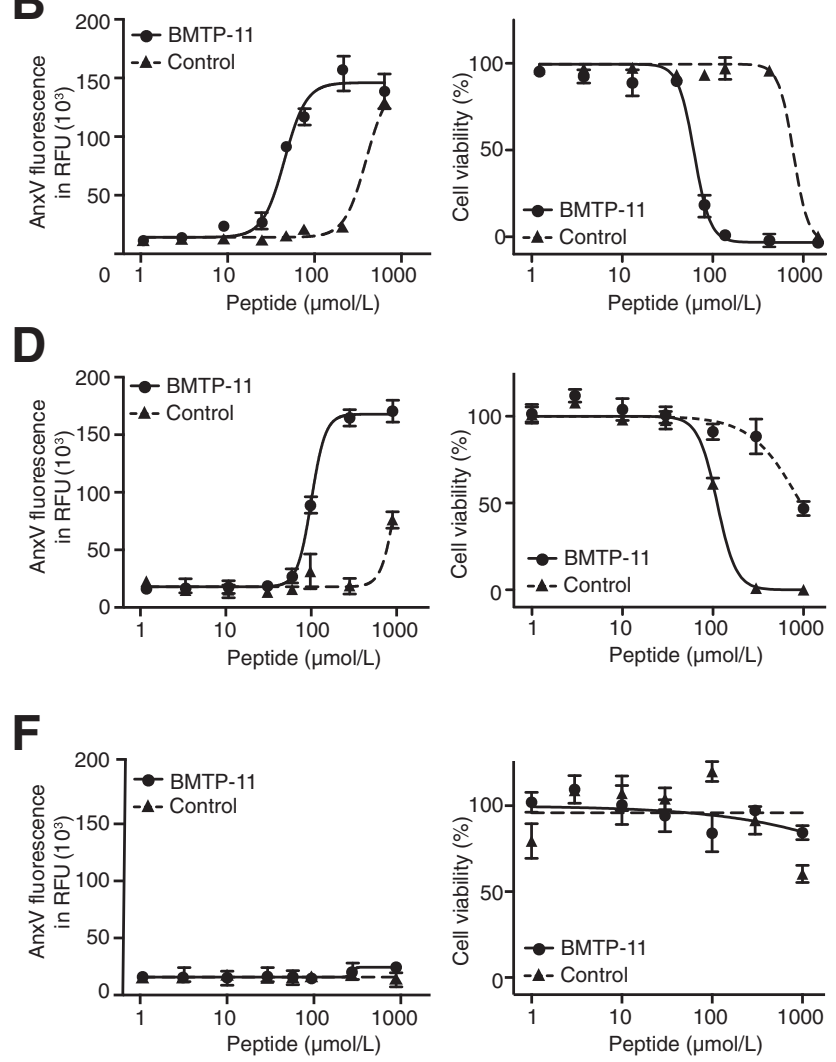

Figure 3 In vitro pharmacologic activity of BMTP-11 on lung cancer cell lines. Cells were treated with serial molar concentrations of BMTP-11 or nontargeted ${ }_{\mathrm{D}}[\mathrm{KLAKLAK}]_{2}$ peptide (control). A-F: Viability was assessed by WST-1 assay at 18 hours after treatments (right panels). Apoptosis was evaluated by Annexin V staining at 6 hours after treatments (left panels). Reverse sigmoidal curves in logarithmic scale for H460 (A), H0P62 (B), H0P92 (C), H226 (D), A549 (E), and H522 (F) treated with BMTP-11 or control. RFU, relative fluorescence unit.

treatment groups: BMTP-11 $(n=10)$ or nontargeted ${ }_{\mathrm{D}}[\mathrm{KLAKLAK}]_{2}$ peptide (control, $n=10$ ). Mice were injected intravenously with either compound on days 3 and 10 after tumor implantation, and tumor volumes were measured every day until the end of the experiment (day 11). In this first preclinical trial, BMTP-11 induced a clear delay in tumor growth compared with the untargeted ${ }_{\mathrm{D}}[\mathrm{KLAKLAK}]_{2}$ (control), which was significant after treatment $(P<0.05)$ (Figure $4 \mathrm{C})$. A similar treatment regimen was applied to the lung colonization model, followed by evaluation of total lung weight plus pulmonary

Table 5 Derived $\mathrm{IC}_{50}$ Values for Cell Viability and Relative Efficacy

\begin{tabular}{lccc}
\hline & \multicolumn{2}{l}{$\mathrm{IC}_{50}(\mu \mathrm{mol} / \mathrm{L})$} & $\begin{array}{r}\text { Relative } \\
\text { efficacy }\end{array}$ \\
\cline { 2 - 3 } Cell lines & $\mathrm{BMTP}-11$ & ${ }_{\mathrm{D}}(\mathrm{KLAKLAK})_{2}$ & \\
\hline H460 & 33 & 208 & 6.3 \\
H0P62 & 47 & 544 & 11.5 \\
H0P92 & 83 & 572 & 6.9 \\
H226 & 111 & 936 & 8.4 \\
A549 & 120 & $>1000$ & $>8.3$ \\
H522 & 972 & $>1000$ & $\sim 1.1$ \\
\hline
\end{tabular}

$\mathrm{IC}_{50}$, concentration that inhibits $50 \%$. tumor count. In this second preclinical trial, administration of BMTP-11 resulted in a reduction in total weight of the lungs $(P<0.0001)$ (Figure 4D) and in the number of lung tumors $(P=0.002)$ (Figure $4 \mathrm{E})$, yet another indication of therapeutic efficacy. No tissue damage was observed by histologic evaluation in the nonmalignant portion of the lungs.

These results indicate that in both preclinical models, BMTP-11 could effectively target the tumor site and inhibit tumor growth.

\section{Discussion}

In this study, we evaluate IL-11R as an unrecognized molecular target in lung cancer and also the efficacy of targeting IL-11R with BMTP-11 in preclinical models of tumor cell lines and tumor-bearing mice. First, we show that IL-11R is highly and consistently expressed in a large panel of surgical lung cancer specimens. Moreover, BMTP-11 is therapeutically active in killing multiple lung cancer cell lines in vitro. Finally, we show that BMTP-11 causes delay in tumor growth in subcutaneous animal models of lung cancer and a reduction in the establishment of tumors in a lung colonization model. 
A
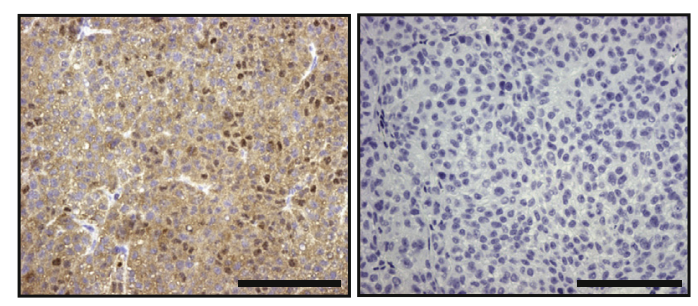

B

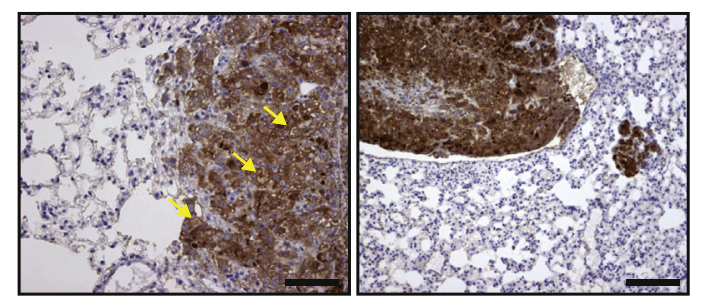

C

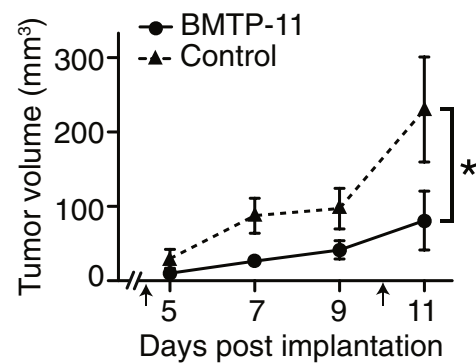

D

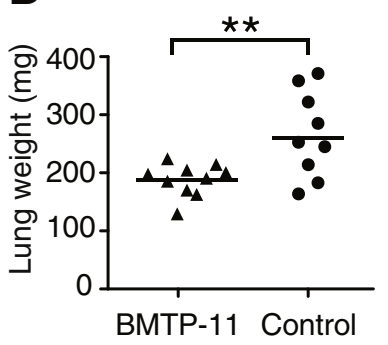

E

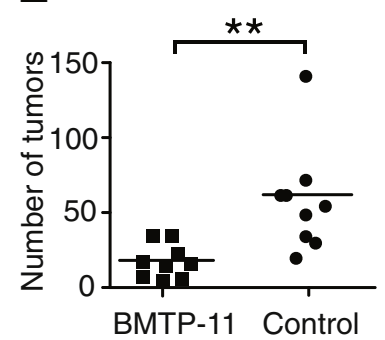

Figure 4 In vivo pharmacologic activity of BMTP-11 in subcutaneous and lung colonization mouse models of human lung cancer. IL-11R expression was evaluated in the mouse models by immunohistochemistry. A: Representative subcutaneous tumor (left) and corresponding control staining with secondary antibody only (right). B: Lung tumor (left) with evidence of membrane IL-11R staining (left, arrows). C: Effect of BMTP-11 treatment on the growth of subcutaneous primary tumors. Mice received an intravenous administration of $10 \mathrm{mg} / \mathrm{kg}$ BMTP-11 or nontargeted ${ }_{D}[K L A K L A K]_{2}$ peptide (control) on days 3 and 10 (arrows). D: Lung weights of mice injected into the tail vein with lung cancer cells and treated with BMTP-11 or control peptide. E: Number of tumors in bilateral lungs dissected from mice treated with either BMTP-11 or control peptide. Data are expressed as mean tumor volumes \pm SEM $($ C). $n=10$ treated mice $(\mathbf{C}-\mathbf{E}) ; n=10$ control mice $(\mathbf{C}) ; n=9$ treated mice $(\mathbf{D}$ and $\mathbf{E}) ;{ }^{*} P<0.05,{ }^{*} P<0.01$. Scale bars: $100 \mu \mathrm{m}(\mathbf{A}$ and $\mathbf{B})$.

High expression of the IL-11R-native ligand, IL-11, has been associated with lung cancer ${ }^{31,32}$ and with the capacity of tumor cells to metastasize to the lungs, ${ }^{33}$ suggesting a functional role in this specific pathologic setting and encouraging the exploitation of IL-11R as a potential therapeutic target. We show that IL-11R is overexpressed in human specimens of primary lung cancer, in which high cytoplasmic levels are associated with receptor presence on the cell membrane. This accumulation of IL-11R at the cell membrane was actually observed also in other cancers, including gastric and colorectal carcinoma. ${ }^{17,18}$ In this light, and because it might be difficult to assess membrane localization in the presence of overwhelming cytoplasmic staining, we propose to adopt the overall expression of IL-11R as a biomarker of potential response to BMTP-11.

Confirming the robust specificity of IL-11R targeting in the tumor, here we report low, cytoplasm-confined levels of IL-11R in human nonmalignant bronchiolar epithelium. It is therefore conceivable that in normal tissue this target is not accessible by an extracellular ligand-directed drug, and, as a consequence, no toxicity is expected to affect the adjacent, nonmalignant lung tissue. This prerequisite is indeed confirmed by our present study and past findings. BMTP-11 has been described as an effective treatment for advanced osteosarcoma, including pulmonary metastasis. ${ }^{16}$ In this study, no in vivo accumulation of BMTP-11 and no damage to nonmalignant lung tissue were described. So far, the only known BMTP-11 toxicity is a dose-dependent, reversible nephrotoxicity, reported in a first-in-man (phase 0) clinical trial in cancer patients. ${ }^{22}$

Here, we also provide evidence of BMTP-11 antitumor activity against lung cancer in vitro and in vivo. In vitro, the observed $\mathrm{IC}_{50}$ for the effects of the targeted drug on cell viability (33 to $120 \mu \mathrm{mol} / \mathrm{L}$ ) are quite promising, also considering that only a portion ( $2 \%$ to $21 \%$ ) of cultured lung cancer cells was positive for detectable surface membrane expression of IL-11R. These effects are attributable to BMTP-11-mediated induction of apoptosis, as we previously reported in prostate cancer cell lines, ${ }^{20}$ and in leukemia and lymphoma cell lines. ${ }^{21}$ In vivo, BMTP-11 was effective in repressing tumor growth both in a subcutaneous tumor xenograft and in a lung colonization model at relatively low molar doses $(10 \mathrm{mg} / \mathrm{kg})$. The higher efficacy of this drug in vivo is possibly related to an increased expression of IL-11R by cancer cells and/or to the observed presence in the vasculature in the tumor stroma. Although such a mechanism will need further validation, one might speculate that BMTP-11 would exert a synergistic effect by acting on both tumor components and on the tumor vasculature.

\section{Conclusions}

We propose BMTP-11 as a candidate drug that should be clinically evaluated in lung cancer patients. Meanwhile, a 
preference for higher scoring in ADC or smokers may help to select subjects with increased expression of IL-11R who would most benefit from IL-11R-targeted therapy, although further investigation is needed. Our results also introduce a new molecular marker of human NSCLC and provide a translational avenue for targeted treatment of patients. Given the ongoing success of translating approved molecularly targeted drugs to additional subsets of cancer patients and the preclinical and pathologic data reported here, we believe that BMTP-11 is a strong candidate drug for a similar translational path.

\section{Acknowledgments}

We thank Dr. Marc Barry for technical assistance with the tissue microarray data.

All authors had full access to the data and take responsibility for the integrity of the data and the accuracy of the data analysis. M.C.-V., F.I.S., and A.J.Z. performed the experiments; G.Y. and J.J.L. performed statistical analysis; M. Sun examined the IHC; C.B. collected the clinical data; W.K.H. and I.I.W. performed pathologic analysis; M.C.-V., S.M., M. Sato, F.I.S., I.I.W., W.A., and R.P. designed the experiments and interpreted the data; M.C.-V., S.M., M. Sato, F.I.S., T.L.S., J.K.B., R.L.S., I.I.W., W.A., and R.P. wrote and edited the manuscript.

\section{Supplemental Data}

Supplemental material for this article can be found at http://dx.doi.org/10.1016/j.ajpath.2016.04.013.

\section{References}

1. Liao Z, Lin SH, Cox JD: Status of particle therapy for lung cancer. Acta Oncol 2011, 50:745-756

2. Tanoue LT, Tanner NT, Gould MK, Silvestri GA: Lung cancer screening. Am J Respir Crit Care Med 2015, 191:19-33

3. American Cancer Society: Cancer Facts \& Figures. Atlanta, GA, American Cancer Society, 2015

4. Siegel RL, Miller KD, Jemal A: Cancer statistics, 2015. CA Cancer J Clin 2015, 65:5-29

5. Scarpaci A, Mitra P, Jarrar D, Masters GA: Multimodality approach to management of stage III non-small cell lung cancer. Surg Oncol Clin N Am 2013, 22:319-328

6. Sandler A, Gray R, Perry MC, Brahmer J, Schiller JH, Dowlati A, Lilenbaum R, Johnson DH: Paclitaxel-carboplatin alone or with bevacizumab for non-small-cell lung cancer. N Engl J Med 2006, 355: 2542-2550

7. Pirker R, Pereira JR, Szczesna A, von Pawel J, Krzakowski M, Ramlau R, Vynnychenko I, Park K, Yu CT, Ganul V, Roh JK, Bajetta E, O'Byrne K, de Marinis F, Eberhardt W, Goddemeier T, Emig M, Gatzemeier U; FLEX Study Team: Cetuximab plus chemotherapy in patients with advanced non-small-cell lung cancer (FLEX): an open-label randomised phase III trial. Lancet 2009, 373:1525-1531

8. Pirker R, Pereira JR, von Pawel J, Krzakowski M, Ramlau R, Park K, de Marinis F, Eberhardt WE, Paz-Ares L, Storkel S, Schumacher KM, von Heydebreck A, Celik I, O'Byrne KJ: EGFR expression as a predictor of survival for first-line chemotherapy plus cetuximab in patients with advanced non-small-cell lung cancer: analysis of data from the phase 3 FLEX study. Lancet Oncol 2012, 13:33-42

9. Rossi A, Maione P, Sacco PC, Sgambato A, Casaluce F, Ferrara ML, Palazzolo G, Ciardiello F, Gridelli C: ALK inhibitors and advanced non-small cell lung cancer (review). Int J Oncol 2014, 45:499-508

10. Solomon BJ, Mok T, Kim DW, Wu YL, Nakagawa K, Mekhail T, Felip E, Cappuzzo F, Paolini J, Usari T, Iyer S, Reisman A, Wilner KD, Tursi J, Blackhall F; PROFILE 1014 Investigators: Firstline crizotinib versus chemotherapy in ALK-positive lung cancer. N Engl J Med 2014, 371:2167-2177

11. Arap W, Kolonin MG, Trepel M, Lahdenranta J, Cardo-Vila M, Giordano RJ, Mintz PJ, Ardelt PU, Yao VJ, Vidal CI, Chen L, Flamm A, Valtanen H, Weavind LM, Hicks ME, Pollock RE, Botz GH, Bucana CD, Koivunen E, Cahill D, Troncoso P, Baggerly KA, Pentz RD, Do KA, Logothetis CJ, Pasqualini R: Steps toward mapping the human vasculature by phage display. Nat Med 2002, 8:121-127

12. Pentz RD, Cohen $\mathrm{CB}$, Wicclair M, DeVita MA, Flamm AL, Youngner SJ, Hamric AB, McCabe MS, Glover JJ, Kittiko WJ, Kinlaw K, Keller J, Asch A, Kavanagh JJ, Arap W: Ethics guidelines for research with the recently dead. Nat Med 2005, 11:1145-1149

13. Staquicini FI, Cardó-Vila M, Kolonin MG, Trepel M, Edwards JK, Nunes DN, Sergeeva A, Efstathiou E, Sun J, Almeida NF, Tu SM, Botz GH, Wallace MJ, O'Connell DJ, Krajewski S, Gershenwald JE, Molldrem JJ, Flamm AL, Koivunen E, Pentz RD, Dias-Neto E, Setubal JC, Cahill DJ, Troncoso P, Do KA, Logothetis CJ, Sidman RL, Pasqualini R, Arap W: Vascular ligand-receptor mapping by direct combinatorial selection in cancer patients. Proc Natl Acad Sci U S A 2011, 108:18637-18642

14. Cardó-Vila M, Zurita AJ, Giordano RJ, Sun J, Rangel R, GuzmanRojas L, Anobom CD, Valente AP, Almeida FC, Lahdenranta J, Kolonin MG, Arap W, Pasqualini R: A ligand peptide motif selected from a cancer patient is a receptor-interacting site within human interleukin-11. PLoS One 2008, 3:e3452

15. Campbell CL, Jiang Z, Savarese DM, Savarese TM: Increased expression of the interleukin-11 receptor and evidence of STAT3 activation in prostate carcinoma. Am J Pathol 2001, 158:25-32

16. Lewis VO, Ozawa MG, Deavers MT, Wang G, Shintani T, Arap W, Pasqualini R: The interleukin-11 receptor alpha as a candidate liganddirected target in osteosarcoma: consistent data from cell lines, orthotopic models, and human tumor samples. Cancer Res 2009, 69: 1995-1999

17. Nakayama T, Yoshizaki A, Izumida S, Suehiro T, Miura S, Uemura T, Yakata Y, Shichijo K, Yamashita S, Sekin I: Expression of interleukin11 (IL-11) and IL-11 receptor alpha in human gastric carcinoma and IL-11 upregulates the invasive activity of human gastric carcinoma cells. Int J Oncol 2007, 30:825-833

18. Yoshizaki A, Nakayama T, Yamazumi K, Yakata Y, Taba M, Sekine I: Expression of interleukin (IL)-11 and IL-11 receptor in human colorectal adenocarcinoma: IL-11 up-regulation of the invasive and proliferative activity of human colorectal carcinoma cells. Int J Oncol 2006, 29:869-876

19. Hanavadi S, Martin TA, Watkins G, Mansel RE, Jiang WG: Expression of interleukin 11 and its receptor and their prognostic value in human breast cancer. Ann Surg Oncol 2006, 13:802-808

20. Karjalainen K, Jaalouk DE, Bueso-Ramos C, Bover L, Sun Y, Kuniyasu A, Driessen WH, Cardó-Vila M, Rietz C, Zurita AJ, O'Brien S, Kantarjian HM, Cortes JE, Calin GA, Koivunen E, Arap W, Pasqualini R: Targeting IL11 receptor in leukemia and lymphoma: a functional ligand-directed study and hematopathology analysis of patient-derived specimens. Clin Cancer Res 2015, 21: 3041-3051

21. Zurita AJ, Troncoso P, Cardó-Vila M, Logothetis CJ, Pasqualini R, Arap W: Combinatorial screenings in patients: the interleukin-11 receptor alpha as a candidate target in the progression of human prostate cancer. Cancer Res 2004, 64:435-439

22. Pasqualini R, Millikan RE, Christianson DR, Cardó-Vila M, Driessen WH, Giordano RJ, Hajitou A, Hoang AG, Wen S, 
Barnhart KF, Baze WB, Marcott VD, Hawke DH, Do KA, Navone NM, Efstathiou E, Troncoso P, Lobb RR, Logothetis CJ, Arap W: Targeting the interleukin-11 receptor alpha in metastatic prostate cancer: a first-in-man study. Cancer 2015, 121:2411-2421

23. Marchiò S, Lahdenranta J, Schlingemann RO, Valdembri $\mathrm{D}$, Wesseling P, Arap MA, Hajitou A, Ozawa MG, Trepel M, Giordano RJ, Nanus DM, Dijkman HB, Oosterwijk E, Sidman RL, Cooper MD, Bussolino F, Pasqualini R, Arap W: Aminopeptidase A is a functional target in angiogenic blood vessels. Cancer Cell 2004, 5: $151-162$

24. Arap MA, Lahdenranta J, Mintz PJ, Hajitou A, Sarkis AS, Arap W, Pasqualini R: Cell surface expression of the stress response chaperone GRP78 enables tumor targeting by circulating ligands. Cancer Cell 2004, 6:275-284

25. Giordano RJ, Lahdenranta J, Zhen L, Chukwueke U, Petrache I, Langley RR, Fidler IJ, Pasqualini R, Tuder RM, Arap W: Targeted induction of lung endothelial cell apoptosis causes emphysema-like changes in the mouse. J Biol Chem 2008, 283:29447-29460

26. De Cesare M, Pratesi G, Veneroni S, Bergottini R, Zunino F: Efficacy of the novel camptothecin gimatecan against orthotopic and metastatic human tumor xenograft models. Clin Cancer Res 2004, 10:7357-7364

27. Kuo TH, Kubota T, Watanabe M, Furukawa T, Kase S, Tanino H, Nishibori H, Saikawa Y, Teramoto T, Ihsibiki K, Kitajima M, Hoffman RM: Orthotopic reconstitution of human small-cell lung carcinoma after intravenous transplantation in SCID mice. Anticancer Res 1992, 12:1407-1410
28. Raso MG, Behrens C, Herynk MH, Liu S, Prudkin L, Ozburn NC, Woods DM, Tang X, Mehran RJ, Moran C, Lee JJ, Wistuba II: Immunohistochemical expression of estrogen and progesterone receptors identifies a subset of NSCLCs and correlates with EGFR mutation. Clin Cancer Res 2009, 15:5359-5368

29. Behrens C, Feng L, Kadara H, Kim HJ, Lee JJ, Mehran R, Hong WK, Lotan R, Wistuba II: Expression of interleukin-1 receptor-associated kinase-1 in non-small cell lung carcinoma and preneoplastic lesions. Clin Cancer Res 2009, 16:34-44

30. Sun M, Behrens C, Feng L, Ozburn N, Tang X, Yin G, Komaki R, Varella-Garcia M, Hong WK, Aldape KD, Wistuba II: HER family receptor abnormalities in lung cancer brain metastases and corresponding primary tumors. Clin Cancer Res 2009, 15:4829-4837

31. Luis-Ravelo D, Anton I, Zandueta C, Valencia K, Ormazabal C, Martinez-Canarias S, Guruceaga E, Perurena N, Vicent S, De Las Rivas J, Lecanda F: A gene signature of bone metastatic colonization sensitizes for tumor-induced osteolysis and predicts survival in lung cancer. Oncogene 2014, 33:5090-5099

32. Wysoczynski M, Ratajczak MZ: Lung cancer secreted microvesicles: underappreciated modulators of microenvironment in expanding tumors. Int J Cancer 2009, 125:1595-1603

33. Calon A, Espinet E, Palomo-Ponce S, Tauriello DV, Iglesias M, Cespedes MV, Sevillano M, Nadal C, Jung P, Zhang XH, Byrom D, Riera A, Rossell D, Mangues R, Massague J, Sancho E, Batlle E: Dependency of colorectal cancer on a TGF-beta-driven program in stromal cells for metastasis initiation. Cancer Cell 2012, 22:571-584 